\title{
La marca territorio como elemento de la comunicación: Factor estratégico del desarrollo turístico en Cuenca
}

\author{
Cristina GonzÁlez OÑate ${ }^{1}$ \\ Universidad Jaume I de Castellón
}

Sonia MARTínez BuENO ${ }^{2}$

Fundación de Cultura Ciudad de Cuenca

Recibido: 04/03/2013

Aceptado: 22/05/2013

\section{Resumen}

La marca de un país, un territorio o una ciudad tiene, como fin primordial, hacer visible la imagen de ese espacio físico entre el público receptor. El peso del turismo en la economía conquense junto con el aumento constante de la competitividad entre destinos, justifica el estudio de su marca. Este artículo tiene como objetivo determinar si la marca e imagen de marca de Cuenca es coherente con su realidad turística y hasta que punto una marca territorio adecuada puede propiciar el desarrollo del sector turístico de un lugar. Para ello se realiza un análisis de la actual marca de Cuenca, se establece su idoneidad, se determinan las funciones básicas y principales características de una marca territorio y se propone un modelo para Cuenca. Palabras Clave: marca; marca territorio; imagen de marca; destino turístico; sistema global de identificación.

The brand territory as a communication: Strategic factor in tourism development in Cuenca

\begin{abstract}
The brand of a country, a region or a city has, as its main goal, to make visible the image of that physical space between the receiving public. The importance of tourism in the Cuenca's economy together with the steady increase competitiveness between destinations, justifies the study of its brand. This article aims to determine if the brand and brand image of Cuenca is consistent with its tourism situation and how far a brand territory can promote proper development of a tourist industry in the area. To do this, it's necessary to perform an análisis of the current brand of Cuenca, sets its suitability, defines the basics functions and main features of a brand territory, and finally proposes a model for Cuenca.
\end{abstract}

Keywords: brand; brand territory; branding; turistic destination; global system of identification.

\footnotetext{
${ }^{1}$ Profesora Contratada Doctora Departamento de Ciencias de la Comunicación. Universidad Jaume I de Castellón. onate@com.uji.es.

${ }^{2}$ Doctora en Ciencias de la Información (Publicidad y RR.PP). Universidad Complutense de Madrid.bpmvillaroman@hotmail.com
} 


\section{Introducción}

La marca es la seña de identidad que define a una empresa, un producto o un servicio. Y, por supuesto, a un territorio. Nadie cuestiona ya que vivimos en un mundo global donde las comunicaciones, Internet, las redes sociales... impregnan cualquier aspecto de nuestra vida cotidiana. Como afirman López Lita y Benlloch ${ }^{3}$, asistimos a una «progresiva tendencia a la uniformidad en cuestión de productos y de productores, de servicios y de demandantes». Es un hecho evidente la estandarización de las necesidades de los consumidores al tiempo que aumenta la oferta de productos y servicios similares, entre los que podemos englobar las actividades culturales, deportivas y, por supuesto, las turísticas. En este contexto, cualquier comunidad que quiera posicionarse como un destino turístico debe comenzar por ser visible para el resto. Y para ser visible ha de estar en condiciones de ofrecer algo que la distinga, que la haga única de todo lo que la rodea. Este artículo no pretende indagar pormenorizadamente en todos los elementos que motivan la elección de una determinada zona como destino turístico, sino que se centrará en el análisis de la marca territorio como activo intangible de un lugar, capaz de aportar un valor añadido que favorezca esa singularidad y promueva la diferenciación en un entorno homogéneo.

Para entender el estudio, parece oportuno realizar un breve recorrido por el turismo conquense y sintetizar algunas definiciones de los conceptos más básicos que se tratan, tales como imagen, marca y marca territorio. Posteriormente se efectuará un examen de la marca turística de Cuenca que ponga de relieve aquellos aspectos que definen e identifican a la ciudad, al tiempo que se evaluará su capacidad para difundir los atractivos de Cuenca. Por último, se propondrá un modelo de Sistema Global de Identificación que tendrá su epicentro en la creación de una marca territorio que sea válida para integrar los atributos tangibles e intangibles de la ciudad y la provincia, de difundirlos entre los diversos públicos receptores y de convertirse en un factor estratégico del desarrollo turístico de Cuenca.

\section{Breve aproximación al turismo en Cuenca: desde los orígenes hasta su consoli- dación}

Cuenca está situada en el corazón de la Península Ibérica, entre Madrid y Valencia. Por tamaño ocupa el $5^{\circ}$ puesto en el ranking nacional. Su población apenas sobrepasa los 219.000 habitantes $^{4}$, lo que la sitúa en la $44^{\text {a }}$ posición. Tiene un total de 238 municipios de los que sólo $11(4,6 \%)$ superan los 3.000 habitantes y $37(15,5 \%)$ los 1.000 , siendo dos (Cuenca capital y Tarancón) los únicos que exceden los 10.000. Estos datos revelan la realidad económica y social de la provincia.

En 1996 la ciudad de Cuenca fue declarada Patrimonio de la Humanidad por la UNESCO. Hasta ese momento, y a pesar de los recursos patrimoniales con los que la capital contaba, el turismo como fuente de riqueza tenía un peso muy modesto en la economía local y provincial. Sin embargo, el desarrollo experimentado por el turismo

${ }^{3}$ LÓPEZ LITA, R. y BENLLOCH, M. T. (2005): «De la marca comercial a la marca territorio», Recerca, Revista de Pensament I Analisi, 5, 88.

4 Datos INE 2011 
cultural en los últimos años ${ }^{5}$ y el notable interés que despiertan entre los turistas los conjuntos históricos declarados Patrimonio de la Humanidad, han provocado un cambio de tendencia. Es importante añadir que dos años después de su declaración como Ciudad Patrimonio, el Ministerio de Economía y Hacienda, la Junta de Comunidades, el Ayuntamiento y la Agrupación Provincial de Hostelería y Turismo de Cuenca suscribieron un convenio marco que permitió la puesta en marcha del Plan de Dinamización Turística $^{6}$, implantado en la ciudad entre 1998 y 2001. Dicho Plan supuso un antes y un después en el desarrollo de su actividad turística, pues fue el primer conjunto de actuaciones llevadas a cabo de forma global y planificada. En total se invirtieron casi tres millones de euros y sentó las bases sobre las que posteriormente se ejecutaría la primera estrategia coordinada para la gestión del turismo conquense ${ }^{7}$.

Uno de los logros más importantes del citado Plan fue la creación de la Fundación Cuenca Ciudad de Congresos, cumpliendo así un objetivo básico que implicaba la actuación conjunta de las administraciones públicas y del sector empresarial en favor del progreso turístico de $\mathrm{Cuenca}^{8}$. A pesar de su nombre, la Fundación no se limitó al desarrollo del turismo de reuniones sino que extendió su trabajo hacia la ordenación y promoción de la actividad turística en la ciudad y su provincia. Buena prueba de ello fue el nacimiento del Observatorio Turístico, resultado de un convenio de colaboración establecido con la Universidad de Castilla-La Mancha. En el año 2004 la Fundación Cuenca Ciudad de Congresos se transformó en la actual Fundación Turismo de Cuenca, cuya finalidad es «coordinar de forma integral la gestión del turismo en la ciudad y provincia de Cuenca [...] y dirige su trabajo a tres productos turísticos básicos: turismo cultural, de reuniones y de naturaleza (que además incluye rural y activo)» ${ }^{9}$.

En cualquier caso, y a pesar de los esfuerzos realizados y del incremento del número de visitantes, Cuenca carece de una posición totalmente consolidada como destino turístico $^{10}$. Es necesario seguir trabajando en el desarrollo de esta actividad que, por otro lado, constituye una de las pocas fuentes de ingresos complementarios con los que cuentan muchas familias de núcleos rurales.

\subsection{Análisis del turismo en Cuenca}

Las motivaciones que inducen a un turista a visitar una ciudad patrimonio de la hu-

${ }^{5}$ BEDATE, A. M.; SANZ, J.A. y HERRERO, L.C. (2001): «Turismo cultural y patrimonio histórico: Aplicación multivariante al estudio de la demanda», Estudios Turísticos, 150, 113132.

${ }^{6}$ PLAN DE DINAMIZACIÓN TURÍSTICA DE CUENCA (2001), Informe final de seguimiento, Cuenca, Ministerio de Economía y Hacienda, Junta de Comunidades de Castilla-La Mancha, Ayuntamiento de Cuenca y Agrupación Provincial de Hostelería y Turismo.

${ }^{7}$ GÓMEZ, M.A.; MONDÉJAR, J.A. y SEVILLA, C. (coords.) (2005): Gestión del turismo cultural y de ciudad, Cuenca, Ediciones de la Universidad de Castilla-La Mancha.

${ }^{8}$ ESTEBAN, A.; MONDÉJAR, J.A. y CORDENTE, M. (2009): «Segmentación de turistas en una ciudad patrimonio de la humanidad», en MONDÉJAR, J.A. y GÓMEZ, M.A. (coord.) (2009): Turismo cultural en ciudades patrimonio de la humanidad, Cuenca, Ediciones de la Universidad de Castilla-La Mancha, 107-128

${ }^{9}$ GÓMEZ, M.A.; MONDÉJAR, J.A. y SEVILLA, C. (2005), op. cit., 168

${ }^{10}$ ESTEBAN, A.; MONDÉJAR, J.A. y CORDENTE, M. (2009), op. cit., 107-128. 
manidad son variadas. Gómez y Mondéjar ${ }^{11}$ establecen siete factores determinantes: disfrute social, vida social, nuevas sensaciones, desarrollo intelectual, naturaleza, relajación y tranquilidad. Además, estos autores desarrollan una tipología de turistas que recoge tres segmentos diferenciados: por un lado, el turista de servicios, que demanda infraestructuras para realizar todo tipo de eventos y actividades (en el caso de Cuenca, es el grupo con el nivel de gasto más elevado); en segundo termino, el turista intermedio (no especializado), que concede importancia a todos los factores sin otorgar relevancia a ninguno y con un nivel de gasto medio; por último, el turista cultural, que busca, precisamente, los atractivos culturales del lugar hasta el que se desplaza (recursos patrimoniales). Es el segmento más joven y con menor nivel de gasto.

Esta clasificación, dada la riqueza patrimonial y cultural existente en la provincia, puede hacerse extensiva a todo su territorio.

La inversión realizada desde 1998 (Plan de Dinamización Turística) y las actuaciones llevadas a cabo posteriormente, propiciaron un incremento del número de turistas en Cuenca, tanto en la capital como en el conjunto de la provincia. Significativas fueron las cifras registradas durante los años 2004 y 2005, tras superar la recesión turística internacional experimentada en 2002 y 2003.

Fig. 1: Viajeros y pernoctaciones de turistas en Cuenca

\begin{tabular}{|l|c|c|c|c|c|c|c|c|c|}
\hline \multirow{2}{*}{ Años } & \multicolumn{4}{|c|}{ Número de viajeros } & \multicolumn{3}{c|}{ Número de pernoctaciones } & $\begin{array}{c}\text { Estancia } \\
\text { media }\end{array}$ \\
\cline { 2 - 10 } & Total & $\begin{array}{c}\text { Tasa de } \\
\text { varia- } \\
\text { ción }\end{array}$ & $\begin{array}{c}\text { Residen- } \\
\text { tes en } \\
\text { España }\end{array}$ & $\begin{array}{c}\text { Residen- } \\
\text { tes en el } \\
\text { extran- } \\
\text { jero }\end{array}$ & Total & $\begin{array}{c}\text { Tasa de } \\
\text { varia- } \\
\text { ción }\end{array}$ & $\begin{array}{c}\text { Residen- } \\
\text { tes en } \\
\text { España }\end{array}$ & $\begin{array}{c}\text { Residen- } \\
\text { tes en el } \\
\text { extran- } \\
\text { jero }\end{array}$ & \\
\hline $\mathbf{2 0 0 1}$ & 298.763 & - & 268.738 & 30.025 & 488.410 & $7,14 \%$ & 443.494 & 44.916 & 1,63 \\
\hline $\mathbf{2 0 0 2}$ & 284.757 & $-4,69 \%$ & 252.387 & 32.370 & 472.649 & $-3,23 \%$ & 425.040 & 47.609 & 1,66 \\
\hline $\mathbf{2 0 0 3}$ & 277.734 & $-2,47 \%$ & 249.689 & 28.045 & 458.100 & $-3,08 \%$ & 413.764 & 44.338 & 1,65 \\
\hline $\mathbf{2 0 0 4}$ & 327.746 & $18,01 \%$ & 297.604 & 30.142 & 546.522 & $19,30 \%$ & 501.738 & 44.784 & 1,67 \\
\hline $\mathbf{2 0 0 5}$ & 348.270 & $6,26 \%$ & 315.732 & 32.538 & 576.129 & $5,42 \%$ & 535.683 & 53.298 & 1,69 \\
\hline $\mathbf{2 0 0 6}$ & 342.364 & $-1,15 \%$ & 310.666 & 31.700 & 579.988 & $2,23 \%$ & 527.997 & 51.994 & 1,69 \\
\hline $\mathbf{2 0 0 7}$ & 374.360 & $9,30 \%$ & 333.001 & 41.359 & 653.815 & $12,7 \%$ & 581.523 & 72.289 & 1,74 \\
\hline $\mathbf{2 0 0 8}$ & 345.883 & $-7,60 \%$ & 307.856 & 38.027 & 615.760 & $-5,82 \%$ & 543.650 & 72.109 & 1,78 \\
\hline $\mathbf{2 0 0 9}$ & 316.418 & $-8,51 \%$ & 277.877 & 38.541 & 558.718 & $-9,26 \%$ & 491.267 & 67.541 & 1,77 \\
\hline $\mathbf{2 0 1 0}$ & 316.384 & $-0,01 \%$ & 272.892 & 43.492 & 533.609 & $-4,49 \%$ & 464.837 & 68.772 & 1,69 \\
\hline $\mathbf{2 0 1 1}$ & 309.729 & $-2,10 \%$ & 266.413 & 43.316 & 504.613 & $-5,43 \%$ & 440.789 & 63.824 & 1,63 \\
\hline
\end{tabular}

FUENTE: elaboración propia a partir del Instituto Nacional de Estadística, $2012^{12}$

${ }^{11}$ GÓMEZ, M.A. y MONDÉJAR, J.A. (2004): «Motivaciones del turista cultural en ciudades Partrimonio de la Humanidad: el caso de Cuenca» en I Congreso Internacional sobre Patrimonio, Desarrollo Rural y Turismo, Osuna, Escuela Universitaria "Francisco Maldonado", Universidad de Sevilla.

${ }_{12}$ Para la elaboración de los gráficos y tablas que aparecen en este artículo se han tenido en cuenta los datos de la Encuesta de Ocupación Hotelera del INE. El motivo es que es el 
Desgraciadamente, la crisis ha afectado al sector turístico internacional y de forma particular, al español. Desde el año 2008 el número de viajeros y de pernoctaciones en Cuenca ha descendido. A ese dato negativo hay que añadir el retroceso experimentado en el promedio de tiempo que un turista permanece en Cuenca: si para el conjunto de España la estancia media se sitúa en el 3,36 (año 2011. INE, EOH), en Cuenca no llega a la mitad, colocándose en el 1,63. Por lo tanto puede concluirse que, además de la disminución en el número de turistas y de pernoctaciones, estamos ante un destino turístico de corta duración. Conviene recordar que el INE no recoge en sus estadísticas oficiales a aquellas personas que se trasladan a un destino turístico sin hospedaje. Y, a la vista de los datos anteriores, parece evidente que Cuenca se conforma como un lugar visitado por excursionistas (según la OMT, viajeros que no pernoctan). Mondéjar et al. ${ }^{13}$ estiman que un $25 \%$ de los turistas de Castilla-La Mancha utilizan esa fórmula. En cuanto a la procedencia de los viajeros que se acercan a esta provincia, la siguiente gráfica muestra cuales son sus principales comunidades de origen:

Fig. 2: Procedencia de los viajeros que visitan Cuenca
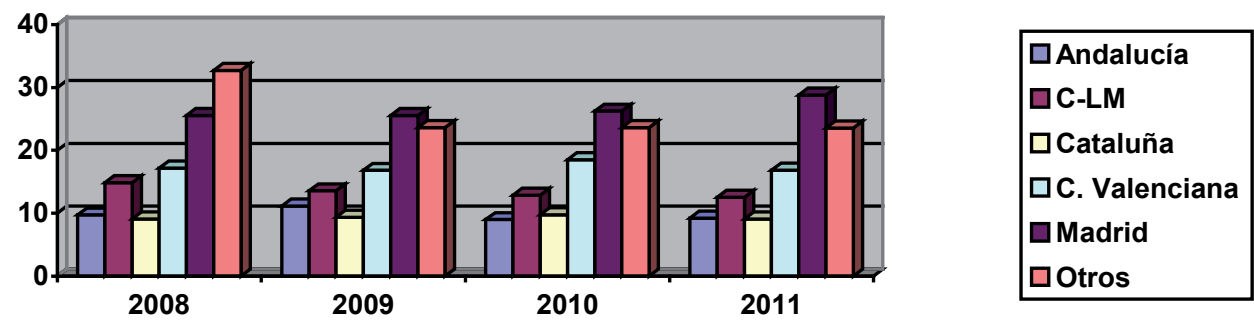

FUENTE: elaboración propia a partir del Instituto Nacional de Estadística, 2012

En función de los datos aportados, puede concluirse, en primer lugar, que los residentes en España constituyen el número más elevado de turistas que visitan Cuenca. Por otro lado, las comunidades autónomas que mayor número de viajeros aportan son Madrid, Comunidad Valenciana, Cataluña y Andalucía, además de la propia Castilla-La Mancha. Y, por último, la duración de la estancia es corta (apenas 1,63 noches de media por visitante).

\section{Una aproximación al concepto de marca territorio}

Internet, las TIC, los cambios políticos, sociales y culturales experimentados en todo el mundo y, especialmente, el fenómeno de la globalización, han logrado derribar las fronteras comunicacionales. Cualquier comunidad, cualquier territorio, es perceptible para el resto del mundo y, a su vez, tiene acceso a ese pangea digital. Sin embargo, único estudio que ofrece sus cifras desglosadas por provincias. No sucede así en las encuestas sobre Ocupación de Campings, Casas Rurales y Apartamentos Turísticos, cuyos datos se refieren, globalizados, a Castilla-La Mancha.

${ }_{13}^{13}$ MONDÉJAR, J.A; MONDÉJAR, J; SEVILLA, C. y CORDENTE, M. (2009): «La Fundación Turismo de Cuenca: Un nuevo modelo de gestión pública y privada», Pasos, Revista de Turismo y Patrimonio Cultural, 7 (2), 281-296. 
esa universalización genera uniformidad. Y la uniformidad, en el caso de un destino turístico, es el obstáculo a superar. De ahí que sea imprescindible incorporar, dentro de la estrategia de marketing, nuevas herramientas capaces de establecer diferencias con los destinos turísticos competidores. Y uno de los instrumentos más eficaces con los que se puede contar es el de la marca territorio. Trasciende, por tanto, su dimensión económica para entrar de lleno a reivindicar identidades geográficas. Porque, como señala Valls ${ }^{14}$, «el concepto de marca es muy amplio y pueden observarse matices muy particulares según sea la perspectiva desde la que se analiza: económica, comercial, legal, publicitaria, etc.».

Kotler ${ }^{15}$ la definía como «un nombre, símbolo o diseño, cuyo propósito es designar los bienes o servicios de un fabricante o grupo de fabricantes y diferenciarlos del resto de los productos o servicios de otros competidores». Pero es también una herramienta estratégica del marketing que vende emociones, sensaciones... atributos intangibles. La marca entabla una relación emocional con los consumidores ${ }^{16}$.

En 1993, Kotler, Haider y Rein ${ }^{17}$ introdujeron el término marketing de ciudades o marketing aplicado al territorio urbanístico. Defendían que, al igual que las empresas, las ciudades necesitan ofrecer al mercado sus productos de forma eficiente $y$, al mismo tiempo, potenciar sus valores y su imagen para que el consumidor final interiorice aquellos atributos que diferencian a cada una del resto. Como afirma Elizagarate ${ }^{18}$, cada ciudad posee cualidades propias y rasgos diferenciales que deben aprovecharse para desarrollar una oferta completa y atractiva que satisfaga las necesidades de potenciales usuarios.

Dentro del sector que nos ocupa, la Organización Mundial de Turismo define la marca de destino como ${ }^{19}$ :

La esencia central y las características perdurables de un destino. Un destino puede cambiar sus estados de ánimo y la manera en que se presenta a sí mismo frente a diferentes segmentos del mercado. Pero sus características centrales de la marca, como la personalidad de un individuo, son esencialmente siempre las mismas. .... Una marca de destino representa una interacción dinámica entre los valores centrales de un destino y la manera en que los visitantes potenciales los perciben. Sólo existe realmente en los ojos de otros. Es la suma de sus percepciones, sentimientos y actitudes hacia el destino.

La definición que aportan sobre destination branding, o marca de destino, Blain, Levy y Brent Ritchie ${ }^{20}$ es una de las más completas que existen:

${ }^{14}$ VALLS, J. F. (1992): La imagen de marca de los países, Madrid, McGraw-Hill, Madrid, 16.

${ }^{15}$ KOTLER, P. (1984): Marketing Management, Prentice-Hall, 482.

${ }^{16}$ LÓPEZ, B. (2006): Marketing y emociones, Madrid, Esic, 12.

${ }^{17}$ KOTLER, P.; HAIDER, D. H. Y REIN, I. (1993): Marketing Places - Attracting Investment, Industry and Tourism to Cities, States and Nations, Nueva York, Free Press.

${ }^{18}$ ELIZAGARATE, V. (2003): Marketing de Ciudades, Madrid, Pirámide.

${ }^{19}$ WORLD TOURISM ORGANIZATION AND THE EUROPEAN TRAVEL COMISIÓN (2009): Handbook on Tourism Destinations Branding, Madrid, World Tourism Organization, XVII.

${ }^{20}$ BLAIN, C.; LEVY, S.E. y BRENT RITCHIE, J.R. (2005): «Destination Branding: In- 
La creación de un nombre, símbolo, logotipo u otro grafismo que identifica y distingue un destino; que comporta la promesa de una experiencia memorable de viaje que se asocia exclusivamente con el destino; y que sirve para consolidar y reforzar la conexión emocional entre el visitante y el destino; que reduce los costes de búsqueda del consumidor y el riesgo percibido; todo con el objetivo de crear una imagen de destino que influya positivamente en la elección del destino por parte del consumidor.

Por lo tanto, la marca de destino tratará de aglutinar aquellas características que le son propias a una zona geográfica y que mejor la identifican y, sobre todo, diferencian del entorno. Si, además, se introduce el concepto de branding entonces se deberá crear esa marca mediante la asociación de un conjunto de valores a un lugar determinado, posicionándolo adecuadamente y generando lazos emocionales positivos entre el turista y el destino. Porque, como afirman Kavaratzis y Ashwort ${ }^{21}$, parece que marketing y branding se han convertido en actividades no sólo comunes sino imprescindibles para ciudades, regiones y países en cualquier lugar del planeta. En esta línea se sitúa también Fernánde ${ }^{22}$ al decir que un proceso de branding es una forma efectiva y singular de incidir en la percepción que el ser humano posee de aquellas realidades de las que apenas dispone de información. Para este autor, el branding no se limita a gestionar un territorio, sino que se concibe como una pieza clave a la hora de elaborar y proyectar una imagen coherente y positiva de un lugar que contribuya a optimizar las percepciones de los públicos y, en definitiva, a mejorar su competitividad global.

Una idea más evolucionada de marca de destino es la que propone Callarisa ${ }^{23}$ al introducir el término de marca territorio y definirlo como un concepto «que recoge las características propias y diferenciales de un territorio y propone una oferta de valor para los diferentes colectivos con los que interactúa, dotándola de una expresión gráfica que facilite su actividad de comunicación». Se convierte así en una herramienta imprescindible a la hora de diferenciar y distinguir entre regiones, de poner de relieve las características más importantes de cada una y de resaltar sus ventajas competitivas y rasgos singulares como destino turístico. Puede ser el imán, el catalizador que atraiga visitantes hacia una determinada entidad geográfica, porque la elección de un territorio como destino turístico va a depender, en mayor o menor medida, de la percepción que las personas tengan de ese lugar.

Por otro lado, al hablar de marca territorio se está trascendiendo el ámbito puramente turístico ${ }^{24}$ para dirigirse también a otros públicos: residentes, inversores, empresasights and Practices from Destination Management Organizations», Journal of Travel Reseach, 43, 337.

${ }^{21}$ KAVARATZIS, M. y ASHWORTH, G.J. (2005): «City Branding: an Effective Assertion of Identity or a Transitory Marketing Trick?», Tijdschrift voor Economische en Sociale Geografie, 96 (5), 507.

${ }^{22}$ FERNÁNDEZ, J. (2010): «Marcas de territorio y comunicación a través de la web: un proyecto de investigación», en Actas del II Congreso Internacional AE-IC Comunicación y Desarrollo en la Era Digital, Málaga: AE-IC, 3-5 febrero.

${ }^{23}$ CALLARISA, L.J (2010): «La identidad del territorio factor estratégico», en: IV Foro Innovem Junts: El territorio, factor estratégico, 5 octubre, 12.

24 HUERTAS, A. (2010): «Las claves del Citybranding», en Institut de la Comunicació, 
rios, estudiantes, etc.

La marca territorio es algo más que una marca de destino puesto que debe servir para comunicar beneficios más allá de los estrictamente turísticos (centro de negocios, centro de estudios, comercial...) y para constituirse en un factor decisivo del desarrollo social, cultural y económico de un lugar. Por este motivo, en este artículo se trata de mostrar su capacidad como elemento fundamental en la gestión integral del territorio: no se trata de vender la cultura de un espacio geográfico, sino de protegerla al tiempo que se promociona su diversidad.

\subsection{Proceso de creación de la marca territorio}

La elaboración de una marca territorio es un proceso complejo y especializado que requiere, antes de nada, una conciencia clara ${ }^{25}$ por parte de los políticos, los gobiernos locales (diputaciones, ayuntamientos, etc.) y los responsables de turismo (asociaciones, fundaciones, etc.), de la necesidad de crear una marca territorio que defina y diferencie a un lugar. Si esos colectivos no son capaces de vislumbrar esa condición y anticipar los beneficios futuros que puede aportar al desarrollo de la zona disponer de ese atributo intangible, cualquier esfuerzo por implementarla será infructuoso.

Por otro lado, y debido a la especial complejidad que entraña el desarrollo de dichas marcas territorio, son varios los autores que argumentan la imposibilidad de su creación o existencia ${ }^{26}$. Objetan que cualquier producto puede cambiar su estrategia de posicionamiento a lo largo del tiempo, pero ese reposicionamiento no es posible cuando se refiere a ciudades, territorios, regiones o países. El razonamiento que aportan es que un producto puede modificar su composición o elaboración y, sin embargo, una realidad geográfica es inmutable: no puede alterar sus tradiciones o su cultura.

En sentido opuesto opinan expertos como Fernández y Huertas ${ }^{27}$, que afirman que una población o ciudad puede gestionar su marca de la misma forma que una empresa cualquiera, y como Elizagarate ${ }^{28}$, que establece un paralelismo entre empresa y ciudad y propugna que el marketing, el branding y las estrategias competitivas son de plena aplicación a los territorios. Incluso Olins ${ }^{29}$, hablando de países, defiende que la imagen de estos ha ido evolucionando y adaptándose a los cambios experimentados, es decir, ha ido reposicionándose con el tiempo.

Lo que sí es cierto es que, dada la variedad de los servicios turísticos ofertados, existen una serie de limitaciones a la hora de crear y desarrollar la marca territorio. En primer lugar, se establece una contraposición entre segmentación y unificación:

Portal de la Comunicació, Bellaterra: Universitat Autónoma de Barcelona, 4

${ }^{25}$ Ibidem, 5.

${ }^{26}$ Ibidem, 4.

${ }^{27}$ FERNÁNDEZ, J. y HUERTAS, A. (2009): «City brands and their communication through websites: Identification of problems and propoals for improvement», en TORRES \& GASCÓ (Eds.), Information Communication Technologies and City Marketing: Digital Opportunities for Cities around the World. Hershey, IGI Global.

${ }^{28}$ ELIZAGARATE, V. (2003), op. cit., 38.

${ }^{29}$ OLINS, W. (2002): «Branding the nation: the historical context», en MORGAN, N.; PRITCHARD, A. y PRIDE, R.(eds.): Destination branding. Creating the unique destination proposition, Oxford, Butterworth-Heinemann, 17-25. 
cualquier lugar puede ser visitado por públicos heterogéneos y por distintos motivos. Por lo tanto, se tiende a la segmentación del mercado y, sin embargo, se crea sólo una marca territorio con un único posicionamiento. Por otro lado, es frecuente hallar, en un mismo territorio, cierta diversidad de marcas (la del Ayuntamiento, Diputación, Oficina de Turismo, etc.). En tercer lugar, es interesante destacar lo que algunos autores definen como experiencia multiservicio ${ }^{30}$ : en cualquier población no existe un único organismo encargado de prestar el servicio turístico. Sucede justo lo contrario: son múltiples y diversos, públicos y privados. Por lo tanto, la experiencia vivida por cada turista derivará de una amplia gama de servicios recibidos. Y, en su inmensa mayoría, son proporcionados por organizaciones ajenas a aquella o aquellas que crean y gestionan la marca territorio. Y en cuarto, y último lugar, la diferenciación, porque el objetivo básico de la marca territorio debe ser definir y diferenciar a aquella zona en la que se aplica del resto del entorno. Sin embargo, con frecuencia se crean marcas basadas en valores que también son utilizados por destinos competidores: modernidad, creatividad, naturaleza, cultura, etc.

Gildo Seisdedo ${ }^{31}$ apunta, además, la incomprensión añadida del término marketing (o citymarketing) entre muchos gestores de ciudades y territorios y su necesaria adaptación a las peculiaridades concretas de este sector.

En cualquier caso, y a pesar de las dificultades expuestas, la imagen de una zona y por extensión el desarrollo de su marca territorio, es imprescindible para el progreso de la misma ${ }^{32}$. tes $^{33}$ :

Los principales pasos a seguir en la creación de una marca territorio son los siguien-

- Análisis y definición de la identidad del territorio: una zona geográfica no puede cambiar su fisonomía, su relieve o su paisaje y tampoco puede modificar lo que hasta ese instante han sido sus tradiciones, sus costumbres o su cultura. En el proceso de creación de una marca territorio deben tenerse en cuenta todos esos factores porque el estudio de los mismos será lo que ayude a definir la identidad del lugar y, al mismo tiempo, a encontrar el atributo/s que marque/n las diferencias con los destinos competidores. Sin embargo, no es necesario que esas características esenciales del territorio formen parte de la marca.

- Proyección de la identidad del territorio: una vez analizados todos los elementos que conforman un lugar, es necesario concretar cuáles son los conceptos más importantes que determinan la identidad de ese territorio.

- Segmentación del mercado: es imprescindible identificar con claridad a qué públicos objetivos se dirigirá la marca territorio. En este sentido, parece evidente

${ }^{30}$ ALLOZA, A. (2002): «La marca experiencia y su papel estratégico en el sector servicios», en DURÁN, Juan José (dir.), Las marcas renombradas españolas. Un activo estratégico para la internacionalización de España, Madrid, McGraw-Hill, 169-181.

${ }^{31}$ SEISDEDOS, G. (2007): Cómo gestionar las ciudades del siglo XXI. Del city marketing al urban management, Madrid, Prentice Hall, 149-153

${ }^{32}$ HUERTAS, A (2010), op. cit., 5.

${ }^{33}$ Elaboración propia a partir de HUERTAS, A. (2010) y el artículo de CHAVES, N.: «Marca gráfica de destino turístico», disponible en www.norbertochaves.com. 
que dicha marca será percibida tanto por aquellos visitantes que acudan a la zona geográfica en cuestión, como por los residentes. Por lo tanto, habrá que distinguir entre públicos internos (instituciones públicas, políticos, empresarios, habitantes, medios de comunicación locales, etc.) y públicos externos (turistas, visitantes, estudiantes, inversores, etc.).

- Posicionamiento del destino: una vez definidos los públicos sobre los que se actuará, será necesario detallar y definir el tipo de posicionamiento que se desarrollará. Es decir, habrá que establecer con precisión el modo en que el territorio desea ser percibido tanto por el público interno como externo.

A partir de aquí se estará en condiciones de abordar la fase de desarrollo conceptual de la marca territorio en función del tipo de estrategia que se considere más adecuada, pero siempre tratando de establecer un paralelismo o concordancia entre la identidad que se quiere transmitir y la imagen que, efectivamente, perciben los diferentes públicos.

Existen diversos modelos gráficos entre los que se puede elegir a la hora de plasmar una marca territorio.

Norberto Chaves ${ }^{34}$ propone cinco estrategias en función del tipo de mensaje predominante: la marca narrativa, la icónica o simbólica, la nacional, la autónoma y la nominal. Puede suceder, y de hecho sucede, que cualquiera de estas estrategias se mezcle o complemente con el resto, lo cual se traduce en múltiples posibilidades y combinaciones a la hora de elegir.

\section{La marca turística «Cuenca, Naturaleza y Cultura»}

La mayoría de los lugares que pugnan por hacerse un hueco como destinos turísticos desarrollan sus propias marcas gráficas, aunque no siempre es necesario que esto suceda pues la marca conceptual no implica obligatoriamente una marca gráfica. Tal y como afirma Norberto Chaves ${ }^{35}$ «la marca gráfica de destino turístico tiene dos misiones: institucionalizar heráldicamente el lugar y sinergizar todas las comunicaciones sectoriales referidas a él». Por lo tanto, será imprescindible tener o crear una marca gráfica cuando un destino turístico quiera darse a conocer o desee ampliar el conocimiento que de él tengan en el exterior. También será oportuno disponer de una marca gráfica cuando se haya puesto en marcha una política turística que establezca, como pilar fundamental, el uso de la propia marca. De ahí deriva su importancia como herramienta de comunicación y como instrumento para competir en el mercado.

Las funciones primordiales de la marca gráfica de un territorio deben ser las de señalar y determinar el territorio en cuestión, es decir, identificarlo como tal.

${ }^{34}$ CHAVES, N. (2006): La imagen corporativa: Teoría y práctica de la identificación institucional, Barcelona, Gustavo Gili. También se ha extraído del artículo «Marca gráfica de destino turístico» de la página web www.norbertochaves.com

${ }^{35}$ CHAVES, N.: «Marca gráfica de un destino turístico», artículo extraído de la página web www.norbertochaves.com 
Fig. 3: Funciones de la marca gráfica

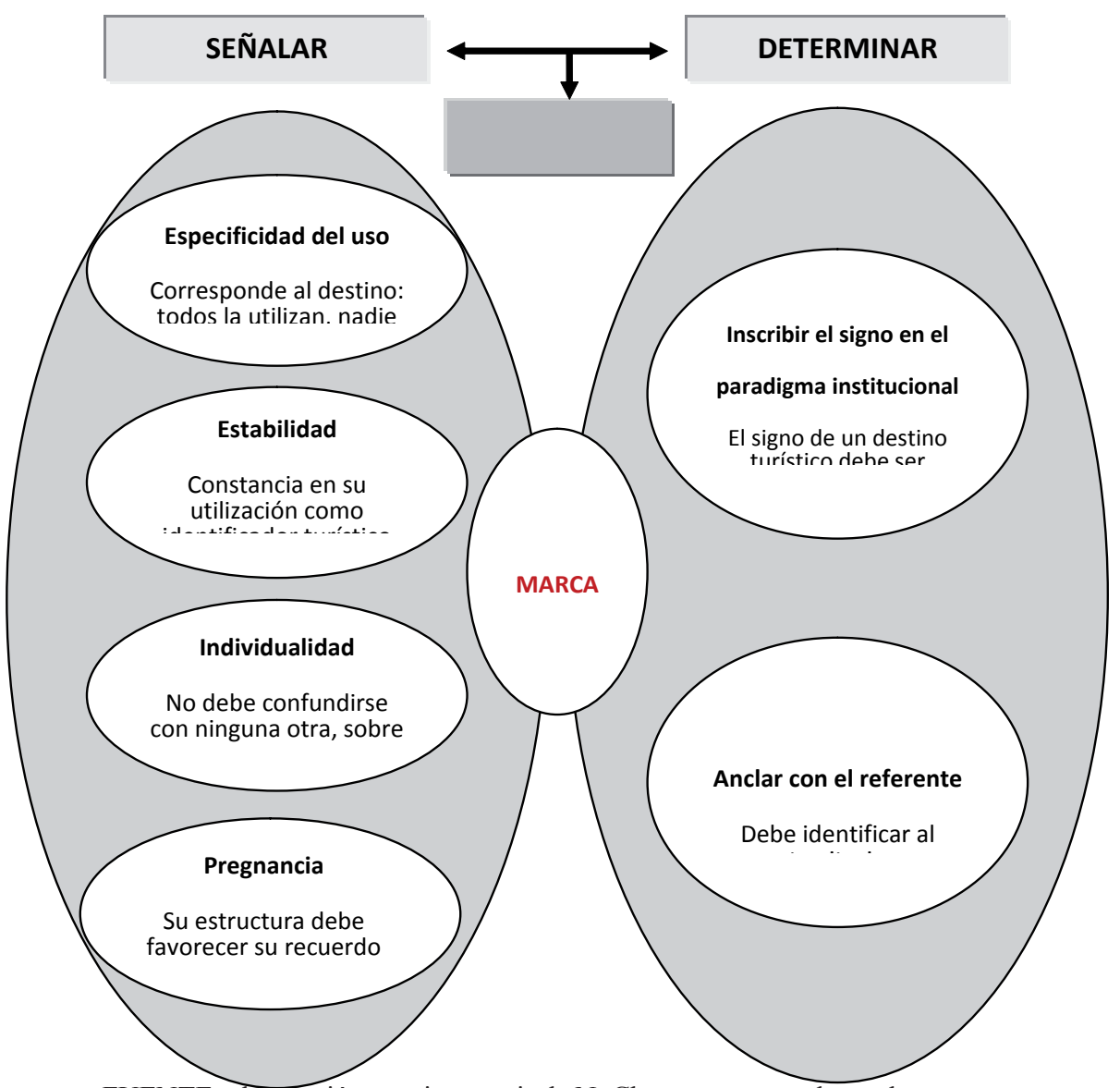

FUENTE: elaboración propia a partir de N. Chaves, www.norbertochaves.com

El objeto de este artículo es demostrar que, además de señalar y determinar, una marca territorio debe diferenciar y distinguir ese lugar del resto.

\subsection{Estudio de la marca turística «Cuenca, Naturaleza y Cultura» ${ }^{36}$}

La actual imagen corporativa de Cuenca se implantó como consecuencia directa de la puesta en marcha del Plan de Dinamización Turística y se creó, como se explica en el propio Manual de Identidad Corporativa ${ }^{37}$ diseñado al efecto, con el objetivo de

${ }^{36}$ Este epígrafe está basado en el Manual de Identidad Corporativa elaborado dentro del Plan de Dinamización Turística y que generosamente fue facilitado por la Fundación Turismo de Cuenca.

${ }^{37}$ PLAN DE DINAMIZACIÓN TURÍSTICA DE CUENCA (2001): Manual de Identidad Corporativa, Cuenca, Ministerio de Economía y Hacienda, Junta de Comunidades de CastillaLa Mancha, Ayuntamiento de Cuenca y Agrupación Provincial de Hostelería y Turismo, 3. 
dotar a la ciudad de Cuenca de una «imagen gráfica y de un sistema de comunicación propios, que permitan al público al que nos dirigimos identificarla y diferenciarla del resto de destinos turísticos de España». Para su desarrollo se tuvieron en cuenta dos de las características más importantes de la ciudad y que mejor la definen: el entorno natural (una situación geográfica privilegiada, entre las hoces del río Júcar y Huécar) y la riqueza cultural (con especial hincapié en las artes plásticas).

La marca turística está formada por tres partes gráficas bien diferenciadas que constituyen lo que se define como «elementos básicos de identificación» a saber, un símbolo, un logotipo y un lema ${ }^{38}$ :

- Símbolo: evoca el carácter vertical de la arquitectura del Casco Antiguo, la irregularidad y el escalado de sus perfiles, así como las formaciones rocosas del entorno mediante una composición de formas abstractas.

- Logotipo: se ha creado una tipografía exclusiva para el logotipo, combinando tipos en caja alta y caja baja. Las serifas de las letras le atribuyen un carácter histórico al que se amoldan perfectamente las formas redondeadas y atrevidas de la $\mathbf{u}$, la $\mathbf{e}$ y la $\mathbf{n}$.

- $[\ldots]$

- Lema: el lema Cuenca, naturaleza y cultura, hace alusión directa a los dos conceptos más representativos de la ciudad. Son dos elementos que definen literalmente lo que el visitante encontrará en Cuenca: la unión entre un entorno geográfico excepcional y una ciudad vital, donde la cultura es el principal protagonista.

Fig. 4: Marca de Cuenca

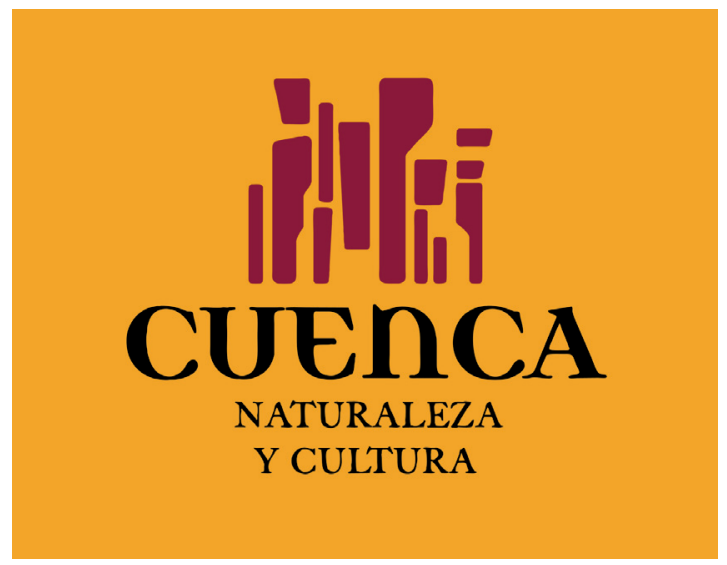

FUENTE: Fundación Turismo de Cuenca

A la vista de las explicaciones del Manual, varias son las conclusiones que pueden extraerse: la primera es que la marca turística de Cuenca se diseñó para ser aplicada en la capital de la provincia y lograr, a través de ella, que fuera identificada y diferenciada del resto de destinos turísticos. La segunda es que tanto el símbolo, como el logotipo y el lema se atribuyen al destino de forma inmediata. El símbolo a través de su dise-

\footnotetext{
${ }^{38}$ Ibidem, 5.
} 
ño abstracto pero reconocible, el logotipo porque indica explícitamente el nombre del lugar y el lema porque recoge dos atributos específicos de Cuenca. La tercera es que se desarrolló en torno a dos características singulares de Cuenca: su entorno natural y sus atractivos culturales que, efectivamente, la definen y la identifican (la señalan y la determinan). Y, por último, la provincia de Cuenca carece de una marca que la identifique como tal.

Desde el punto de vista de las cinco estrategias marcarias ideadas por Norberto Chaves, parece claro que la marca turística de Cuenca es una mezcla de algunas de ellas: por un lado, se encuadra dentro lo que el autor denomina marca icónica, es decir, se apoya en esas líneas que sugieren uno de los signos de identidad de Cuenca, sus Casas Colgadas, sus perfiles escalados de la Hoz del Río Júcar y del Río Huécar. Lo hacen con cierto nivel de abstracción, pero fácilmente reconocibles e identificables. Por otro lado, además de ese anclaje icónico, utiliza el verbal: estamos pues ante una marca nominal, que confía en el nombre del destino como vehículo portador de la identidad del lugar. Esto presupone que el territorio posee un conjunto de significados que son públicamente reconocidos tanto dentro como fuera de sus fronteras. Pero, además, y dado el lema utilizado, la representación simbólica del entorno y el propio nombre recogido en el logotipo, también podría hablarse de una marca narrativa, es decir, aquella que apuesta por describir el lugar y sus características más visibles y elige una imagen representativa del destino.

Una vez realizado este estudio de la marca gráfica, será interesante comprobar hasta qué punto coincide el posicionamiento deseado de la misma con la imagen que se tiene de Cuenca por parte de residentes, visitantes, empresarios y profesionales del sector.

\subsection{Análisis de la imagen de marca de Cuenca ${ }^{39}$}

No existen estudios específicos que analicen la marca e imagen de marca de Cuenca como destino turístico. Sin embargo, hay dos documentos de trabajo del Sistema de Investigación Turística de Castilla-La Mancha (en adelante SITdCLM) que aportan información sobre el tema. El primero de ellos (año 2008) ${ }^{40}$ analizó la marca turística y la imagen de marca de Castilla-La Mancha entre distintos grupos de profesionales y empresarios del sector turístico de la región. En uno de sus apartados (3.2. Análisis de la imagen del destino por provincias) se solicitó a los participantes que, de forma espontánea, expresaran tres ideas o conceptos que definieran a las provincias en las que residían. El objetivo del estudio era elaborar «la imagen individual de cada provincia como destino turístico». Las conclusiones más importantes a las que se llegó, con respecto a Cuenca, fueron las siguientes: los conceptos «serranía» y «paisajes» son los que

${ }^{39}$ Este epígrafe está basado en dos documentos de trabajo del Sistema de Investigación Turística de Castilla-La Mancha: La marca turística de Castilla-La Mancha (2008) e Imagen y marca turística de Castilla-La Mancha (2009), facilitados por el Observatorio Turístico de Cuenca.

${ }^{40}$ INSTITUTO DE PROMOCIÓN TURÍSTICA DE CASTILLA-LA MANCHA (2008): La marca turística de Castilla-La Mancha. Sistema de Investigación Turística de Castilla-La Mancha 12 (SITdCLM), Toledo, Instituto de Promoción Turística de Castilla-La Mancha y Universidad de Castilla-La Mancha. 
otorgan a la provincia de Cuenca un carácter único. Son dos elementos relacionados con la imagen de naturaleza que se muestra en su marca turística; sin embargo, el concepto «naturaleza» no es distintivo de Cuenca, sino que es común a todas las provincias de Castilla-La Mancha. Y otro tanto sucede con el de «cultura». Por lo tanto, existe adecuación entre imagen y marca, pero no exclusividad. Además, también se pidió que se indicara el grado de adecuación de dicha provincia con los diferentes tipos de turismo estudiados. Los resultados obtenidos concluyeron que Cuenca se percibe como un destino bastante adecuado para el turismo de naturaleza y de patrimonio. Sin embargo, el grado de adecuación existente en el turismo de congresos-reuniones es inferior al de otras provincias.

El segundo informe del SITdCLM (año 2009) ${ }^{41}$, llevó a cabo el mismo tipo de análisis, pero esta vez entre grupos de empresas turísticas, residentes y visitantes en Castilla-La Mancha, así como entre esos tres segmentos en cuatro regiones españolas: La Rioja, Andalucía, Castilla y León y Extremadura. Los datos obtenidos se referían a dos universos distintos: residentes y visitantes y ponían de relieve las diferencias existentes entre ambos con respecto a las ideas asociadas a la provincia de Cuenca. Los residentes opinaron que los elementos más representativos de la provincia de Cuenca eran: las Casas Colgadas (24.1\%); la naturaleza (10.2\%); el conjunto patrimonial y cultural (8.8\%); la arquitectura (7.3\%) y la ciudad de Cuenca (5.8\%). Sobre el total de las ideas aportadas, esos cinco elementos suponen el 56.2\%. Además, si nos centramos en aquellos conceptos que se relacionan con Cuenca con carácter único, el porcentaje que se alcanza es el $41.5 \%$ y de ellos hay dos (Casas Colgadas y Cuenca ciudad) que se sitúan entre los cinco elementos más importantes relacionados con Cuenca.

Para los visitantes, la provincia conquense se definía a través de: las Casas Colgadas (19.5\%); la naturaleza (10.5\%); Cuenca ciudad (7.4\%); gastronomía (7\%); Serranía de Cuenca $(5.8 \%)$ y vino (5.1\%). Esos seis conceptos suman el $55.3 \%$ del total. Y, fijándonos en aquellos elementos de carácter único, éstos alcanzan la cifra del 34.3\%. Puede concluirse que sí existen algunas diferencias en las ideas o conceptos asociados a Cuenca entre residentes y visitantes. Es interesante destacar, en este sentido, que sean los visitantes los que relacionan la provincia con gastronomía, castillos, deportes de aventura y vino en mayor medida que los residentes y que estos últimos lo hagan con las Casas Colgadas, el conjunto patrimonial, la arquitectura y el río Cuervo.

En cuanto al grado de adecuación de los diferentes productos turísticos, el estudio pone de manifiesto que, tanto para residentes como para visitantes, Cuenca es considerada como un destino turístico muy adecuado para la práctica del turismo de patrimonio, rural y de naturaleza. Sin embargo, el turismo de congresos y reuniones obtiene un grado de adecuación medio y sigue siendo inferior al de otras provincias.

${ }^{41}$ INSTITUTO DE PROMOCIÓN TURÍSTICA DE CASTILLA-LA MANCHA (2009): Imagen y marca turística de Castilla-La Mancha. Sistema de Investigación Turística de Castilla-La Mancha 12 (SITdCLM), Toledo, Instituto de Promoción Turística de Castilla-La Mancha y Universidad de Castilla-La Mancha. 
Fig. 5: Grado de adecuación de los productos turísticos entre residentes y visitantes

\begin{tabular}{|c|c|c|}
\hline Tipos productos turísticos & $\begin{array}{c}\text { Grado adecuación } \\
\text { Residentes }\end{array}$ & $\begin{array}{c}\text { Grado adecuación } \\
\text { Visitantes }\end{array}$ \\
\hline \multirow[t]{3}{*}{ T. Activo y ecoturismo } & \multirow[t]{3}{*}{ Todas provincias adecuadas } & - Cuenca: 7.37 \\
\hline & & - Albacete: 6.36 \\
\hline & & - Ciudad Real: 6.20 \\
\hline \multirow[t]{3}{*}{ T. Salud y bienestar } & - Albacete: 6.87 & - Cuenca: 7.20 \\
\hline & \multirow[t]{2}{*}{ - Ciudad Real: 6.67} & - Albacete: 6.54 \\
\hline & & - Ciudad Real: 6.17 \\
\hline \multirow[t]{3}{*}{ T. Rural y naturaleza } & - Cuenca: 8.16 & - Guadalajara: 8.34 \\
\hline & - Albacete: 8.12 & - Albacete: 8.23 \\
\hline & - Ciudad Real: 7.93 & - Cuenca: 7.96 \\
\hline \multirow[t]{3}{*}{ T. Enológico } & - Ciudad Real: 8.36 & - Ciudad Real: 7.87 \\
\hline & - Toledo: 7.41 & - Albacete: 7.24 \\
\hline & - Albacete: 7.22 & - Guadalajara: 6.16 \\
\hline \multirow[t]{3}{*}{ T. Congresos y reuniones } & \multirow[t]{3}{*}{ - Toledo: 5.55} & - Cuenca: 5.73 \\
\hline & & - Albacete: 5.25 \\
\hline & & - Toledo: 5.01 \\
\hline \multirow[t]{3}{*}{ T. Gastronómico } & - Ciudad Real: 8.53 & \multirow[t]{3}{*}{ Todas provincias adecuadas } \\
\hline & - Cuenca: 7.8 & \\
\hline & - Toledo: 7.65 & \\
\hline \multirow[t]{2}{*}{ T. Patrimonio } & - Toledo: 8.42 & - Toledo: 9 \\
\hline & - Cuenca: 8.18 & - Cuenca: 8.51 \\
\hline
\end{tabular}

FUENTE: elaboración propia a partir de SITdCLM 2009.

Las puntuaciones se establecieron sobre una base de 10

Por lo que respecta al resto de España, es escasa la información y los estudios comparativos realizados sobre las marcas turísticas de las provincias españolas. A modo de ejemplo, citar que la empresa Oak Power ${ }^{42}$ (2011) llevó a cabo una investigación entre 600 periodistas de todo el mundo especializados en turismo. El objetivo fue conformar un mapa que mostrara el posicionamiento mediático internacional de las diferentes marcas turísticas españolas. Dicho estudio concluyó, con referencia a destinos culturales, de patrimonio y naturaleza, que Madrid era la ciudad española con mejor imagen de marca (9.1 puntos de media), seguida de Barcelona (8.7) y Sevilla (7.9). Toledo obtuvo 7.5 puntos. En cuanto a destinos culturales, destacan: Madrid (Museo del Prado, 9.3 puntos), Granada (Alhambra, 9.2), Sevilla (8.5), Toledo (8.1), Barcelona (8), Bilbao

${ }^{42}$ OAK POWER COMUNICACIÓN (2011): Estudio Oak Power de las marcas turísticas españolas en la prensa internacional. Disponible en: www.oakpowergrupo.com 
(7.9). Y la marca de naturaleza más valorada: el Camino de Santiago (8.6), seguida de Asturias (8.2), Pirineos (7.9) y Huelva (Doñana, 7.8). Cuenca no apareció en ninguno de los rankings descritos.

\subsection{Cuenca ¿es un destino de naturaleza y cultura? Propuesta de un modelo de posicionamiento corporativo: del branding a la marca territorio integrada.}

Para que un producto turístico se convierta en destino turístico es indispensable que, además de disponer de recursos, éstos estén integrados con los servicios, sean de calidad y susceptibles de ser comunicados a los públicos, tanto internos como externos. Todo el patrimonio que posee Cuenca, natural y cultural, se encuentra repartido a lo largo y ancho de su geografía. Esta circunstancia puede convertirse en un arma de doble filo: por un lado favorece el impulso del sector que nos ocupa al propiciar la actividad turística en todo el territorio de la provincia y al implicar, necesariamente, el desplazamiento del usuario hasta los lugares que visita, facilitando así la actividad transversal de otras empresas relacionadas (artesanía, comercio, cultura, deporte o gastronomía) y ayudando a las economías familiares de los núcleos rurales, predominantemente agrícolas y ganaderas, que ven en el turismo una posibilidad de desarrollo sostenible. Pero, en contraposición, cuando la extensión del territorio es considerable y el nivel demográfico bajo, se produce una gran dispersión en la localización geográfica de esos recursos y, en muchos casos, un deficiente tratamiento de los mismos desde el punto de vista de su aprovechamiento turístico.

Cuenca posee una red de comunicaciones aceptable (autovías, tren de alta velocidad, ferrocarril convencional...) que, unida a su situación geográfica, la podrían convertir en un destino preferente para el turismo de interior. Sin embargo, la deficiente oferta de transporte público interno (sobre todo entre la ciudad y algunos lugares de singular interés) dificulta los desplazamientos para aquellos visitantes que no disponen de vehículo propio. Por otro lado, todavía existen numerosos bienes del patrimonio arqueológico, civil, religioso o natural que, por su falta de adecuación y por una deficiente dotación de servicios, distan mucho de poder ser utilizados como productos turísticos. Además, escasea la oferta de actividades complementarias, como es el caso de los deportes de aventura ${ }^{43}$.

No obstante, a la vista de lo expuesto y de todos los datos aportados en el epígrafe anterior, podría concluirse que, efectivamente, Cuenca es un destino turístico que ofrece naturaleza y cultura y así es percibido por residentes y visitantes: la declaración de Cuenca como Ciudad Patrimonio de la Humanidad por la UNESCO y el abundante patrimonio existente en toda la provincia la convierten en un destino cultural de interior. Por otro lado, el entorno natural que el turista puede encontrar, tanto en la capital como en el resto de la provincia, es rico y variado. La Ciudad Encantada y el nacimiento del Río Cuervo son dos de los elementos que eran percibidos por residentes y visitantes como exclusivos y únicos de Cuenca.

${ }^{43}$ ADESIMAN (2005): Plan estratégico de marketing turístico para los territorios de la Mancha Alta y la Serranía Media de Cuenca, Grupo de Acción Local Federación para el Desarrollo de la Sierra y Mancha Conquense (ADESIMAN). Disponible en www.adesiman.org 
Por tanto, existe adecuación entre la marca (el lema) y su posicionamiento. Pero aún cuando la marca turística «Cuenca, naturaleza y cultura» define a la ciudad y cabe la posibilidad de ser utilizada también por la provincia, podríamos formular la siguiente pregunta: ¿Aporta alguna característica diferencial con relación al resto de las provincias de la comunidad o incluso con respecto a otros destinos turísticos de interior?

Si la función de una marca turística es identificar al lugar y, además, proporcionar ese valor añadido, ese rasgo distintivo, ese atributo que establece la diferencia con los demás competidores, parece evidente (una vez analizados los datos aportados) que no cumple la función de distinguir. Recordar brevemente que Toledo, dentro de CastillaLa Mancha, era mejor valorada entre residentes y visitantes como destino turístico cultural y que Guadalajara obtenía mejores cifras, entre los visitantes, en el apartado de turismo de naturaleza. Por ello ha llegado el momento de retomar e impulsar el espíritu del Plan de Dinamización Turística, haciéndolo extensivo a la provincia, con el propósito de articular una estrategia coherente que aglutine a todos los agentes implicados en la toma de decisiones y que coordine las actuaciones necesarias encaminadas a mejorar los diversos productos turísticos, su promoción, comercialización y comunicación. Y, dentro de esa comunicación, es prioritaria la creación de una identidad corporativa que vaya más allá de la elaboración de una marca turística y su puesta en valor (branding) o del desarrollo de un manual que diga, de forma exhaustiva, cómo debe aplicarse esa marca. Es necesario caminar hacia el diseño de un sistema global de identificación que conlleve un posicionamiento corporativo y una estrategia de identidad y comunicación. Por lo tanto, se hace imprescindible la creación de una marca territorio que, superando las barreras actuales, defina y distinga a Cuenca (capital y provincia) como destino turístico.

A continuación se propone un modelo de marca territorio para Cuenca: 


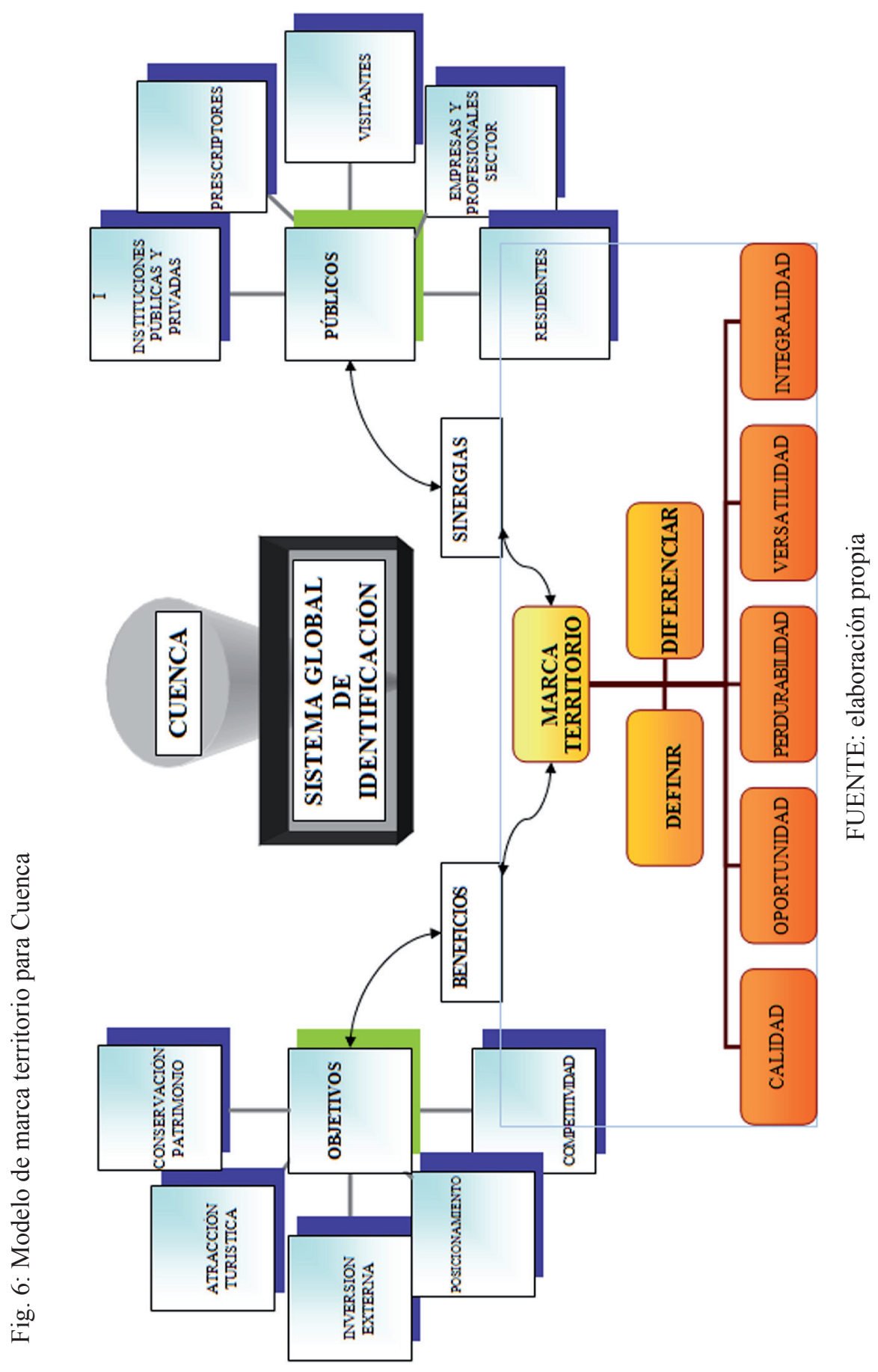


Este modelo pone de relieve la importancia que están adquiriendo los sistemas globales de identificación ${ }^{44}$ en el seno de cualquier organización y, por supuesto, también en la gestión de los territorios. Y dentro de ellos, y como uno de sus elementos más importantes (aunque no el único), las marcas territorio.

Como se explicaba en la Introducción, asistimos a una estandarización de necesidades al tiempo que se homogeniza la oferta de productos y servicios. Los destinos turísticos no escapan de este efecto globalizador y, si quieren atraer visitantes, deben ofrecer singularidad y visibilidad. Ya no es suficiente poseer recursos culturales, naturales, gastronómicos, artesanales, etc., y disponer de una marca que los venda y de un manual de identidad corporativa que describa cómo se debe utilizar. Como afirman Galmés y Victoria ${ }^{45}$, hay que «replantearse el proceso de planificación de las comunicaciones de marca y construir la integración a partir de un planteamiento estratégico"». En definitiva, se está evolucionando hacia un sistema global de identificación donde no sólo es necesario el diseño de una estrategia sino también el control integral y especializado de la misma. Y, dentro de ese sistema, es imprescindible evolucionar desde la marca de destino (orientada a los turistas y ampliamente desfasada ${ }^{46}$ ) hacia una marca territorio que supere esa primitiva concepción y sea capaz de llegar a públicos más amplios y diversos, empleando todas los recursos a su alcance (incluidas, por supuesto, las herramientas 2.0, capaces de fomentar la interacción entre usuarios y destino). Por otro lado, es necesario también aprovechar las sinergias que pueden surgir entre la marca territorio (cuyo uso controlado y especializado beneficiará a los públicos que la utilicen) y el resto de marcas consolidadas que pueden existir en la zona (ciudad y provincia). Una buena marca territorio, creada a partir de las características descritas, estará en condiciones de favorecer el logro de los objetivos descritos y, por lo tanto, un desarrollo sostenible del entorno que garantice la conservación del patrimonio cultural y natural existente en la actualidad.

\section{Conclusiones}

Con este trabajo se ha tratado de poner de relieve la importancia que una marca apropiada, capaz de definir y diferenciar un espacio geográfico, puede tener en el desarrollo turístico de un territorio. Se ha realizado una aproximación al concepto de marca turística, definiéndola como la combinación de atributos tangibles (todos los recursos culturales y naturales de que dispone una ciudad, zona o región) e intangibles (recursos emocionales), que se dirige a turistas (reales y potenciales) y cuyo objetivo es hacer atractivo ese lugar para atraer visitantes. A continuación, y tratando de dar un paso más allá, se ha profundizado en el concepto de marca territorio, lo que implica dar vida a un término que, además de reunir aquellas características que son propias y diferenciales de un lugar, le aporta un valor añadido para llegar a públicos más amplios que los pu-

${ }^{44}$ CHAVES, N. (2012): «Tres generaciones en el diseño corporativo», artículo extraído de la página web www.norbertochaves.com

${ }^{45}$ GALMÉS, M. y VICTORIA, J.S. (2012): «La organización de eventos en el contexto de las Comunicaciones Integradas de Marketing (IMC): el valor de la experiencia», Pensar la Publicidad. Revista Internacional de Investigaciones Publicitarias, 6 (1), 25.

${ }^{46}$ JIMÉNEZ, M. (2012): «El Co-Country Branding: una estrategia turística de innovación comercial en el mediterráneo europeo», Entelequia, 14, 209-235. 
ramente turísticos.

Cuenca, objeto de estudio, es considerada como un destino turístico adecuado para la práctica del turismo de patrimonio, rural y de naturaleza. El análisis de la marca turística «Cuenca, naturaleza y cultura» ha confirmado que reúne dos de los atributos tangibles más importantes que posee la ciudad y su provincia. Pero no la distingue, no aporta ningún rasgo diferencial con respecto a otros destinos competidores, dentro y fuera de Castilla-La Mancha. Se limita a describir una realidad. Y ese es el motivo por el que, en este artículo, se realiza una propuesta de sistema global de identificación dentro del cual se desarrolle una marca territorio capaz de unificar la ciudad y la provincia, que aproveche sinergias y que actúe como motor de desarrollo. Una marca territorio que, en definitiva, logre transmitir y amoldar la identidad de un espacio geográfico con la imagen de marca que de él tienen o perciben los diferentes públicos. Y para ello se hace imprescindible encontrar ese atributo que defina a Cuenca y, al mismo tiempo, la diferencie del resto porque cada territorio posee elementos únicos que hay que saber identificar para, posteriormente, comunicar en términos precisos y definitorios.

\section{Bibliografía citada}

ADESIMAN (2005): Plan estratégico de marketing turístico para los territorios de la Mancha Alta y la Serranía Media de Cuenca, Grupo de Acción Local Federación para el Desarrollo de la Sierra y Mancha Conquense (ADESIMAN). http:// ww.adesiman.org. Web visitada el 25/5/2012.

ALLOZA, A. (2002): «La marca experiencia y su papel estratégico en el sector servicios», en DURÁN, J.J. (dir.), Las marcas renombradas españolas. Un activo estratégico para la internacionalización de España, Madrid, McGraw-Hill, 169-181.

BEDATE, A.M.; SANZ, J.A. y HERRERO, L.C. (2001): «Turismo cultural y patrimonio histórico: Aplicación multivariante al estudio de la demanda», Estudios Turisticos, 150, 113-132

BLAIN, C.; LEVY, S. E. y BRENT RITCHIE, J.R. (2005): «Destination Branding: Insights and Practices from Destination Management Organizations», Journal of Travel Reseach, 43, 328-338.

CALLARISA, L. J. (2010): «La identidad del territorio factor estratégico», en IV Foro Innovem Junts: El territorio, factor estratégico, 5 de octubre, http://www.innovemjuntcv.org. Web visitada el 15/6/2012.

CHAVES, N. (2006): La imagen corporativa: Teoría y práctica de la identificación institucional, Barcelona, Gustavo Gili.

CHAVES, N., (2012a): «Marca gráfica de un destino turístico», http://www.norbertochaves.com. Web visitada el 10/6/2012.

- (2012b): «Tres generaciones en el diseño corporativo», http://www.norbertochaves. com. Web visitada el 18/6/2012.

CONSEJERÍA DE MEDIO AMBIENTE Y DESARROLLO RURAL (2008): Plan Estratégico de Desarrollo Sostenible del Medio Rural de Castilla-La Mancha, Toledo, Servicio de Publicaciones de la Junta de Comunidades de Castilla-La Mancha.

ELIZAGARATE, V. (2003): Marketing de Ciudades, Madrid, Pirámide.

ESTEBAN, A. y MONDÉJAR, J. A. y CORDENTE, M. (2009): «Segmentación de 
turistas en una ciudad patrimonio de la humanidad», en MONDÉJAR, J. A. y GÓMEZ, M. A. (coord.), Turismo cultural en ciudades patrimonio de la humanidad, Cuenca, Ediciones de la Universidad de Castilla-La Mancha, 107-128.

FERNÁNDEZ, J. y HUERTAS, A. (2009): «City brands and their communication through websites: Identification of problems and propoals for improvement», en TORRES \& GASCÓ (Eds.), Information Communication Technologies and City Marketing: Digital Opportunities for Cities around the World, Hershey, IGI Global. FERNÁNDEZ CAVIA, J. (2010): «Marcas de territorio y comunicación a través de la web: un proyecto de investigación», en Actas del II Congreso Internacional AE-IC Comunicación y Desarrollo en la Era Digital, Málaga: AE-IC, 3-5 febrero.

GALMÉS CEREZO, M. y VICTORIA MAS, J.S. (2012): «La organización de eventos en el contexto de las Comunicaciones Integradas de Marketing (IMC): el valor de la experiencia», Pensar la Publicidad. Revista Internacional de Investigaciones Publicitarias, 6 (1), 15-34.

GÓMEZ, M. A. y MONDÉJAR, J. A. (2004): «Motivaciones del turista cultural en ciudades Patrimonio de la Humanidad: el caso de Cuenca», en I Congreso Internacional sobre Patrimonio, Desarrollo Rural y Turismo, Osuna, Universidad de Sevilla, Escuela Universitaria "Francisco Maldonado".

GÓMEZ, M. A.; MONDÉJAR, J. A. y SEVILLA, C. (coords.) (2005): Gestión del turismo cultural y de ciudad, Cuenca, Ediciones de la Universidad de Castilla-La Mancha.

HUERTAS, A. (2010): «Las claves del Citybranding», en Institut de la Comunicació, Portal de la Comunicació, Bellaterra: Universitat Autónoma de Barcelona, http:// www.portalcomunicacion.com/esp/pdf/aab_lec/57.pdf. Web visitada el 8/6/2012.

INSTITUTO NACIONAL DE ESTADÍSTIC̄A, Encuesta de Ocupación Hotelera (2001 a 2011). http://www.ine.es. Web visitada el 20/5/2012.

INSTITUTO DE PROMOCIÓN TURÍSTICA DE CASTILLA-LA MANCHA (2008): La marca turística de Castilla-La Mancha. Sistema de Investigación Turística de Castilla-La Mancha 12 (SITdCLM), Toledo, Instituto de Promoción Turística de Castilla-La Mancha y Universidad de Castilla-La Mancha.

http://www.turismocastillalamancha.com/investigación/. Web visitada el 28/5/2012.

- (2009): Imagen y marca turística de Castilla-La Mancha. Sistema de Investigación Turística de Castilla-La Mancha 12 (SITdCLM), Toledo, Instituto de Promoción Turística de Castilla-La Mancha y Universidad de Castilla-La Mancha. http://www. turismocastillalamancha.com/investigación/. Web visitada el 30/5/2012.

JIMÉNEZ, M. (2012): «El Co-Country Branding: una estrategia turística de innovación comercial en el mediterráneo europeo», Entelequia, 14, 209-235.

KAVARATZIS, M. y ASHWORTH, G.J. (2005): «City Branding: an Effective Assertion of Identity or a Transitory Marketing Trick?», Tijdschrift voor Economische en Sociale Geografie, 96 (5), 506-514.

KOTLER, P. (1984): Marketing Management, Prentice-Hall, 482.

KOTLER, P.; HAIDER, D. H. Y REIN, I. (1993): Marketing Places - Attracting Investment, Industry and Tourism to Cities, States and Nations, Nueva York, Free Press. LÓPEZ, B. (2006): Marketing y emociones, Madrid, Esic, 12. 
LÓPEZ LITA, R. y BENLLOCH, M. T. (2005): «De la marca comercial a la marca territorio», Recerca, Revista de Pensament I Analisi, 5, 87-100.

MONDÉJAR, J. A.; MONDÉJAR, J; SEVILLA, C. y CORDENTE, M. (2009): «La Fundación Turismo de Cuenca: Un nuevo modelo de gestión pública y privada», Pasos, Revista de Turismo y Patrimonio Cultural, 7 (2), 281-296. http://redalyc. uaemex.mx/src/inicio/ArtPdfRed.jsp?iCve $=88111635010$

Web visitada el 14/5/2012.

OAK POWER COMUNICACIÓN (2011): Estudio Oak Power de las marcas turísticas españolas en la prensa internacional. http://www.oakpowergrupo.com. Web visitada el 18/6/2012.

OLINS, W. (2002): «Branding the nation: the historical context», en MORGAN, N.; PRITCHARD, A. y PRIDE, R.(eds.): Destination branding. Creating the unique destination proposition, Oxford, Butterworth-Heinemann, 17-25.

PLAN DE DINAMIZACIÓN TURÍSTICA DE CUENCA (2001a): Informe final de seguimiento, Cuenca, Ministerio de Economía y Hacienda, Junta de Comunidades de Castilla-La Mancha, Ayuntamiento de Cuenca y Agrupación Provincial de Hostelería y Turismo.

- (2001b): Manual de Identidad Corporativa, Cuenca, Ministerio de Economía y Hacienda, Junta de Comunidades de Castilla-La Mancha, Ayuntamiento de Cuenca y Agrupación Provincial de Hostelería y Turismo.

SEISDEDOS, G. (2007): Cómo gestionar las ciudades del siglo XXI. Del city marketing al urban management. Madrid, Prentice Hall.

VALLS, J. F. (1992): La imagen de marca de los países, Madrid, McGraw-Hill, 16.

WORLD TOURISM ORGANIZATION AND THE EUROPEAN TRAVEL COMISIÓN (2009): Handbook on Tourism Destinations Branding, Madrid, World Tourism Organization, p. XVII. 